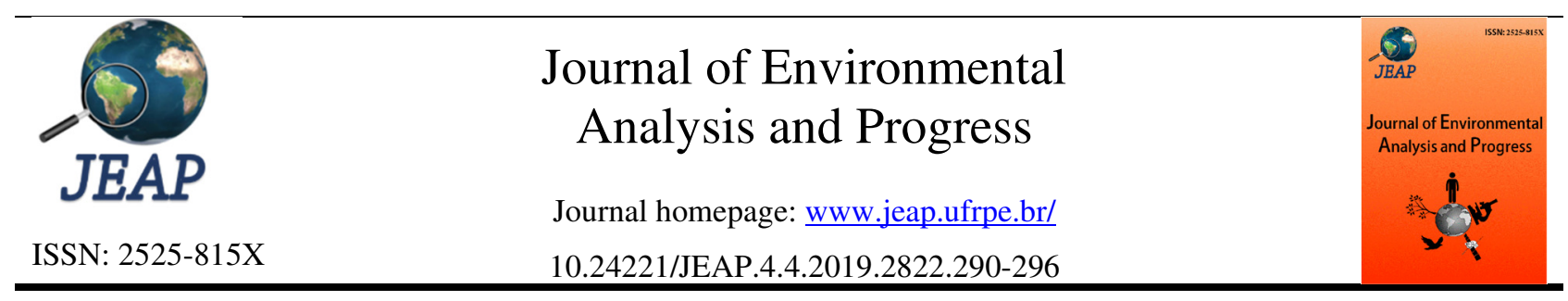

\title{
Gestão ambiental em publicações científicas nacionais: uma revisão sistemática
}

\section{Environmental management in national scientific publications: a systematic review}

Alexsandro Bezerra Correia Bilar ${ }^{\mathrm{a}}$, Adriny Horrany Gomes da Silva ${ }^{\mathrm{a}}$, Andreza Cecília de Siqueira Silva $^{a}$, Cícera Maria da Silva ${ }^{a}$, Ellen Karoline de Souza ${ }^{a}$, Idaiane Bernardino dos Santos ${ }^{a}$, Flávia Fernanda da Silva Mourab ${ }^{\mathrm{b}}$ Catarina Rosa e Silva de Albuquerque

a Universidade Federal Rural de Pernambuco-UFRPE, Unidade Acadêmica de Serra Talhada, Av. Gregório Ferraz de Nogueira, s/n, José Tomé de Souza Ramos, Serra Talhada/PE. CEP 56909-535. E-mail: alexsandrobilar@yahoo.com.br.

b Faculdade de Integração do Sertão-FIS, Rua João Luiz de Melo, n. 2110, Tancredo Neves, Serra Talhada/PE. CEP: 56909-205.

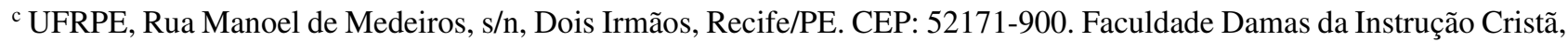
Avenida Rui Barbosa, 1426-B, Graças, Recife/PE. CEP: 52050-000.

\begin{abstract}
A R T I C L E I N F O
Recebido 21 Out 2019

Aceito 22 Out 2019

Publicado 31 Out 2019

A B S T R A C T

Environmental management is a concept that has different approaches and can be restricted to the field of business management or be more comprehensive and involve the management and proper handling of natural resources, as well as other conservationist practices. The objective of the study was to describe the main interpretations that have been given to the term "environmental management" in scientific studies published in this country over the last years. A systematic literature review of the articles published during the period from 2009 to 2018, posted on the Scielo platform, was proceeded. It was found that most of the research surveyed were related to the areas of quality and production management, with emphasis on analyses, systems and environmental certifications, highlighting studies on industries in the south and southeast of Brazil. However, recently, multi and interdisciplinary researches have been conducted, with greater scope, including through partnerships between national researchers and other countries.
\end{abstract}

Keywords: Environmental conservation, natural resources, sustainability.

\section{R E S U M O}

A gestão ambiental é um conceito que possui diferentes abordagens, podendo restringir-se ao campo da gestão empresarial ou ser mais abrangente e envolver o gerenciamento e manejo adequado dos recursos naturais, bem como outras práticas conservacionistas. $\mathrm{O}$ objetivo do estudo foi descrever as principais interpretações que vem sendo dadas ao termo "gestão ambiental" nos estudos científicos publicados neste país ao longo dos últimos anos. Procedeu-se uma revisão sistemática de literatura dos artigos publicados durante o período de 2009 a 2018, indexados na plataforma Scielo. Constatou-se que a maior parte das pesquisas levantadas relacionaram-se às áreas de gestão da qualidade e da produção, com ênfase em análises, sistemas e certificações ambientais, destacando-se estudos sobre indústrias do Sul e Sudeste do Brasil. Entretanto, recentemente, vêm sendo realizadas pesquisas multi e interdisciplinares, com maior abrangência, inclusive através de parcerias entre pesquisadores nacionais e de outros países.

Palavras-Chave: Conservação ambiental, recursos naturais, sustentabilidade.

\section{Introdução}

A partir dos alertas gerados, ao longo de décadas, pela Conferência de Estocolmo, em 1972, as crises do petróleo, a publicação do Relatório Brundtland, em 1987, a Eco-92, a Rio+10, em 2002, e a Rio +20 , em 2012, a sociedade passou a 
perceber que a conservação da natureza possui um inquestionável papel para a manutenção da qualidade de vida neste planeta, sendo necessários o gerenciamento e o manejo adequado dos recursos naturais.

Os visíveis reflexos negativos causados ao meio ambiente pelas atividades antrópicas evidenciam, de acordo com Galvíncio \& Queiroz (2015), a obrigatoriedade de um constante aprimoramento das atividades de monitoramento, planejamento e gerenciamento dos recursos ecossistêmicos.

Dentres tais atividades nocivas à natureza, merecem destaque as realizadas pelas empresas através de suas operações, o que demonstra a atualidade e a relevância da temática gestão ambiental. No entanto, esse assunto possui diferentes abordagens por parte dos autores nacionais em seus estudos publicados.

Curi (2011) relaciona gestão ambiental, à gestão da qualidade, ao considerar que ambas tratam da satisfação dos clientes e da elevação da eficiência dos processos produtivos (incluindo as certificações de qualidade, ecoeficiência e sistema de gestão ambiental), e acrescenta que essa pauta passou a efetivamente integrar a agenda dos atuais dirigentes das organizações privadas, haja vista que está diretamente ligada a sua sobrevivência econômica.

Autores como Barbieri (2016) e Seiffert (2014) possuem uma visão mais abrangente acerca da gestão ambiental, ao englobarem a mensuração dos impactos das atividades produtivas na biodiversidade através de uma perspectiva interdisciplinar, assim como a relevância da responsabilidade socioambiental das organizações.

Rodrigues \& Silva (2013) relembram que a gestão ambiental temo como fundamental propósito o meio ambiente, buscando assegurar a adequação dos meios de exploração dos recursos socioculturais, naturais e econômicos.

Nesse sentido, esta pesquisa faz o seguinte questionamento: de que maneira a gestão ambiental vem sendo abordada nos estudos publicados no Brasil no decorrer dos anos?

Portanto, o principal objetivo desta investigação foi descrever, através de uma revisão sistemática da literatura, as principais interpretações que vêm sendo dadas ao termo "gestão ambiental" nos estudos científicos publicados neste país, ao longo dos últimos anos.

\section{Material e Métodos}

O presente estudo classifica-se como exploratório e descritivo quanto aos fins e, como uma pesquisa bibliográfica, do tipo revisão sistemática de literatura, quanto aos meios, conforme Lakatos \& Marconi (2003) e Gil (2008).

A pesquisa envolveu um levantamento dos artigos existentes na plataforma Scielo, escolhida em função de sua importância e abrangência, referente aos anos de 2009 a 2018, considerando, para a filtragem, todos os anos e áreas temáticas, em cujos títulos e palavras-chave constassem o termo: "gestão ambiental", no idioma português, tendo em vista que o estudo visou as publicações nacionais.

Foram considerados apenas os periódicos científicos com, no mínimo, três artigos publicados sobre esse tema, durante esse período.

Optou-se por uma abordagem qualitativa para a análise dos dados, com aplicação da técnica análise de conteúdo temático, de acordo com Bardin (2011), que orienta a organização, categorização e inferência dos dados levantados em seus respectivos contextos.

No intuito de subsidiar tal análise, utilizouse o recurso nuvem de palavras, ferramenta disponível on line através do site WordArt.com. Na nuvem, as palavras mais frequentes no texto aparecem em tamanho maior. Esse artifício facilitou a identificação das palavras mais recorrentes nos estudos científicos pesquisados. Entretanto, a análise realizada não se restringiu a uma mera averiguação de frequência de palavras.

\section{Resultados e Discussão}

Foram encontrados 124 artigos científicos nacionais, abordando o tema "gestão ambiental", durante o período de 2009 a 2018, na plataforma Scielo.

Os periódicos que se destacaram em quantidade de publicações foram: Gestão \& Produção, do Departamento de Engenharia de Produção da Universidade Federal de São Carlos, com 17 artigos; Ambiente e Sociedade, vinculado à Associação Nacional de Pós-Graduação e Pesquisa em Ambiente e Sociedade, com 13; Engenharia Sanitária e Ambiental, da Associação Brasileira de Engenharia Sanitária e Ambiental, com 12; e Production, da Associação Brasileira de Engenharia da Produção, com 11. Isso aponta uma considerável vinculação dessa temática às áreas da gestão da produção e da qualidade, ratificando a visão de Curi (2011), que relaciona o conceito de gestão ambiental a essas respectivas áreas.

Considerando a abordagem dada à expressão gestão ambiental nessas publicações, notou-se grande ênfase aos estudos relacionados às análises, indicadores, certificações e sistema de gestão ambiental, apesar da existência de pesquisas de caráter interdisciplinar. Na Figura 1 são exibidas 
as palavras mais recorrentes nos títulos dos artigos pesquisados.

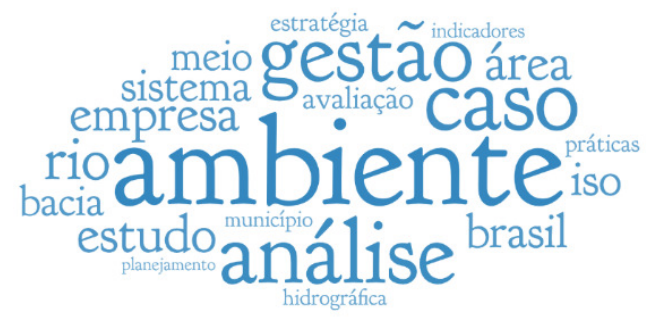

Figura 1. Nuvem de palavras criada a partir dos títulos dos artigos pesquisados, depositados na base de dados Scielo. Fonte: site WordArt.com.

Merecem destaque, na nuvem exibida na Figura 1, as palavras: caso, análise, estudo, empresa e sistema, além, obviamente, de ambiente e gestão. Analisando os contextos e as perspectivas das publicações relacionadas a esses termos, infere-se a existência de um predomínio de estudos de casos empresariais, através de análises e avaliações de sistemas de gestão e dos impactos ou possíveis impactos ambientais cometidos por atividades organizacionais. Isto reforça a importância do que Galvíncio \& Queiroz (2015) chamaram de aprimoramento do gerenciamento dos recursos ecossistêmicos.

A Figura 2 mostra os termos mais recorrentes e constantes no levantamento das palavras-chave dos textos científicos analisados. Esta figura evidencia as palavras: gestão, ambiente, sistema, urbano, ISO e indicador.

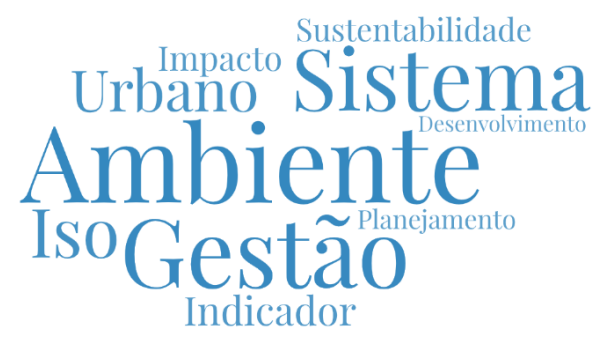

Figura 2. Nuvem de palavras criada a partir das palavras-chave presentes nos artigos analisados, depositados na base de dados Scielo. Fonte: site WordArt.com.

Analisando-se os respectivos artigos, pode-se inferir que estudos em meio urbano e abordando indicadores ambientais, tais como os previstos na ABNT NBR ISO 14000, norma que especifica os requisitos de um Sistema de Gestão Ambiental e permite às organizações desenvolverem uma estrutura para operarem de maneira mais sustentável e economizando recursos, em consonância, novamente, com a perspectiva de Curi (2011), segundo a qual a gestão ambiental também gera ganhos econômicos para as empresas.

Em relação aos temas centrais dos artigos levantados, sobressaíram-se: planos, estratégias, ferramentas e sistemas de gestão ambiental, particularmente em estudos realizados em indústrias localizadas nas regiões Sul e Sudeste.

Pode-se inferir, a partir da análise desses dados, que os estudos publicados em periódicos nacionais relacionados à gestão ambiental, na maioria das vezes, voltam seus olhares para empresas do ramo industrial, as quais, de fato, possuem um maior potencial de geração de impactos negativos ao meio ambiente, muitas das quais instaladas próximas a rios e a cidades com grande densidade populacional.

No Quadro 1 constam os artigos científicos publicados no ano de 2010 e depositados na plataforma Scielo, seus autores, títulos, temas centrais e respectivos periódicos.

Quadro 1. Artigos científicos abordando a gestão ambiental, publicados no ano de 2010, depositados na base de dados Scielo. Fonte: Bilar et al. (2019).

\begin{tabular}{|c|c|c|c|}
\hline Autoria/Ano & Título do artigo & Tema central & Revista \\
\hline $\begin{array}{c}\text { Fonseca; Martins } \\
(2010)\end{array}$ & $\begin{array}{c}\text { Gestão ambiental: uma súplica do planeta, um } \\
\text { desafio para políticas públicas, incubadoras e } \\
\text { pequenas empresas }\end{array}$ & $\begin{array}{c}\text { Reflexão sobre o papel das } \\
\text { incubadoras de empresas no apoio } \\
\text { a práticas ambientais. }\end{array}$ & Production \\
\hline $\begin{array}{c}\text { Calegari et al } \\
(2010)\end{array}$ & $\begin{array}{c}\text { Análise da dinâmica de fragmentos florestais } \\
\text { no município de Carandaí, MG, para fins de } \\
\text { restauração florestal }\end{array}$ & $\begin{array}{c}\text { Aplicação da gestão agroambiental } \\
\text { para a conservação e restauração de } \\
\text { áreas degradadas. }\end{array}$ & Revista Árvore \\
\hline $\begin{array}{c}\text { Freitas; Almeida } \\
(2010)\end{array}$ & $\begin{array}{c}\text { Avaliação do nível de consciência ambiental } \\
\text { em meios de hospedagem: uma abordagem } \\
\text { exploratória }\end{array}$ & $\begin{array}{c}\text { Nível de conscientização ambiental } \\
\text { a partir das práticas adotadas por } \\
\text { hotéis. }\end{array}$ & $\begin{array}{c}\text { Sociedade \& } \\
\text { Natureza }\end{array}$ \\
\hline $\begin{array}{c}\text { Fonseca; Souza e } \\
\text { Jabbour (2010) }\end{array}$ & $\begin{array}{c}\text { Desafios e oportunidades das incubadoras de } \\
\text { empresas para a incorporação de estratégias } \\
\text { ambientais }\end{array}$ & $\begin{array}{c}\text { Incubadoras como instrumentos de } \\
\text { políticas públicas para a promoção } \\
\text { de práticas ambientais. }\end{array}$ & $\begin{array}{c}\text { Organizações \& } \\
\text { Sociedade }\end{array}$ \\
\hline Rego (2010) & $\begin{array}{c}\text { Recursos genéticos, biodiversidade, } \\
\text { conhecimento tradicional Kaiowá e Guarani e } \\
\text { o desenvolvimento local }\end{array}$ & $\begin{array}{c}\text { Relatos sobre a recuperação de } \\
\text { vegetação remanescente em } \\
\text { Kaiowá e Guarani. }\end{array}$ & $\begin{array}{c}\text { Interações (Campo } \\
\text { Grande) }\end{array}$ \\
\hline
\end{tabular}




\begin{tabular}{|c|c|c|c|}
\hline $\begin{array}{c}\text { Alperstedt et al. } \\
(2010)\end{array}$ & $\begin{array}{c}\text { Estratégias de gestão ambiental e seus fatores } \\
\text { determinantes: uma análise institucional }\end{array}$ & $\begin{array}{c}\text { Fatores determinantes das } \\
\text { estratégias de gestão ambiental das } \\
\text { empresas industriais catarinenses. }\end{array}$ & $\begin{array}{c}\text { Revista de } \\
\text { Administração de } \\
\text { Empresas }\end{array}$ \\
\hline $\begin{array}{c}\text { Uehara et al } \\
(2010)\end{array}$ & $\begin{array}{c}\text { Pesquisas em gestão ambiental: análise de sua } \\
\text { evolução na Universidade de São Paulo }\end{array}$ & $\begin{array}{c}\text { Evolução dos grupos que realizam } \\
\text { pesquisas em gestão ambiental na } \\
\text { USP. }\end{array}$ & $\begin{array}{c}\text { Ambiente \& } \\
\text { Sociedade }\end{array}$ \\
\hline $\begin{array}{c}\text { Grael; Oliveira } \\
(2010)\end{array}$ & $\begin{array}{c}\text { Sistemas certificáveis de gestão ambiental e da } \\
\text { qualidade: práticas para integração em } \\
\text { empresas do setor moveleiro }\end{array}$ & $\begin{array}{c}\text { Práticas de integração de sistemas } \\
\text { certificáveis de gestão ambiental e } \\
\text { de qualidade sob um estudo de } \\
\text { caso. }\end{array}$ & Production \\
\hline $\begin{array}{c}\text { Oliveira; Serra } \\
(2010)\end{array}$ & $\begin{array}{c}\text { Benefícios e dificuldades da gestão ambiental } \\
\text { com base na ISO 14001 em empresas } \\
\text { industriais de São Paulo }\end{array}$ & $\begin{array}{c}\text { Adoção de Sistemas de Gestão } \\
\text { Ambiental ISO 14001 em empresas } \\
\text { industriais em SP }\end{array}$ & Production \\
\hline $\begin{array}{c}\text { Oliveira; } \\
\text { Pinheiro (2010) }\end{array}$ & $\begin{array}{c}\text { ISO 14001: uma contribuição da área de gestão } \\
\text { de pessoas }\end{array}$ & $\begin{array}{c}\text { Estudos de caso sob implantação de } \\
\text { sistemas de gestão ambiental ISO } \\
\text { 14001. }\end{array}$ & Gestão \& Produção \\
\hline $\begin{array}{c}\text { Sellitto, et al. } \\
(2010)\end{array}$ & $\begin{array}{c}\text { Modelagem para avaliação de desempenho } \\
\text { ambiental em operações de manufatura }\end{array}$ & $\begin{array}{c}\text { Apresentação e teste de um método } \\
\text { para a mensuração de desempenho } \\
\text { ambiental. }\end{array}$ & Gestão \& Produção \\
\hline $\begin{array}{c}\text { Varjabedian } \\
(2010)\end{array}$ & Lei da Mata Atlântica: retrocesso ambiental & $\begin{array}{c}\text { Compreensões e análises legais no } \\
\text { tocante a Mata Atlântica. }\end{array}$ & Estudos Avançados \\
\hline $\begin{array}{c}\text { Mechi; Sanches } \\
(2010)\end{array}$ & $\begin{array}{c}\text { Impactos ambientais da mineração no Estado } \\
\text { de São Paulo }\end{array}$ & $\begin{array}{c}\text { Impactos da mineração no meio } \\
\text { ambiente; desafios para prevenção } \\
\text { e mitigação. }\end{array}$ & Estudos Avançados \\
\hline
\end{tabular}

Foram identificados 13 artigos depositados na plataforma Scielo, publicados no ano de 2010, envolvendo o tema gestão ambiental.

Analisando-se os dados presentes no Quadro 1, confirmam-se as constatações citadas anteriormente acerca das principais revistas e das abordagens temáticas relacionadas à gestão ambiental escolhidas pelos autores, os quais dão preferência às análises de sistemas de gestão ambiental empresariais e suas correlações, principalmente com as áreas de produção e qualidade no âmbito industrial.

O Quadro 2 traz um resumo dos 14 artigos publicados no ano de 2018, no idioma português, depositados na base de dados Scielo, sobre o tema gestão ambiental, evidenciando um modesto incremento do número de produções científicas existentes naquela plataforma, em comparação com o ano de 2010. Isto representa um aumento de apenas $7,7 \%$.

Quadro 2. Artigos científicos sobre gestão ambiental, publicados em português, no ano de 2018, depositados na base de dados Scielo. Fonte: Bilar et al. (2019).

\begin{tabular}{|c|c|c|c|}
\hline Autoria/Ano & Título do artigo & Tema central & Revista \\
\hline $\begin{array}{l}\text { Ceconi et al. } \\
\text { (2018) }\end{array}$ & $\begin{array}{c}\text { Análise de vulnerabilidade visando o } \\
\text { planejamento ambiental em bacia de captação } \\
\text { para abastecimento público }\end{array}$ & Suscetibilidade natural do solo à erosão & $\begin{array}{l}\text { Ambiente \& } \\
\text { Sociedade }\end{array}$ \\
\hline $\begin{array}{l}\text { Assis, Ribeiro } \\
\text { \& Moraes } \\
\quad(2018)\end{array}$ & $\begin{array}{c}\text { Proposição de melhorias para o Sistema de } \\
\text { Cobrança pelo Uso da Água Bruta da Bacia } \\
\text { Hidrográfica do Rio São Francisco }\end{array}$ & $\begin{array}{c}\text { Sistema de cobrança, aspectos passíveis } \\
\text { de aperfeiçoamento e simulando as } \\
\text { modificações propostas para a Região } \\
\text { Hidrográfica } \\
\end{array}$ & $\begin{array}{l}\text { Engenharia } \\
\text { Sanitária e } \\
\text { Ambiental }\end{array}$ \\
\hline $\begin{array}{l}\text { Amazonas, } \\
\text { Silva \& } \\
\text { Andrade } \\
(2018)\end{array}$ & $\begin{array}{c}\text { Gestão ambiental hoteleira: tecnologias e práticas } \\
\text { sustentáveis aplicadas a hotéis }\end{array}$ & $\begin{array}{l}\text { Incorporação de tecnologias e práticas } \\
\text { sustentáveis, responsabilidade } \\
\text { socioambiental dos hotéis. }\end{array}$ & $\begin{array}{l}\text { Ambiente \& } \\
\text { Sociedade }\end{array}$ \\
\hline $\begin{array}{c}\text { Pereira, } \\
\text { Paredes \& } \\
\text { Okawa }(2018) \\
\end{array}$ & $\begin{array}{l}\text { Diagnóstico preliminar da integridade ambiental } \\
\text { de fundos de vale }\end{array}$ & $\begin{array}{l}\text { Integridade ambiental, diagnóstico e } \\
\text { tomada de decisões quanto a } \\
\text { intervenção nessas áreas }\end{array}$ & $\begin{array}{l}\text { Engenharia } \\
\text { Sanitária e } \\
\text { Ambiental }\end{array}$ \\
\hline $\begin{array}{l}\text { Nascimento \& } \\
\text { Gomes (2018) }\end{array}$ & $\begin{array}{c}\text { Planejamento e orçamento municipal de Teresina } \\
\text { para o crescimento econômico e meio ambiente } \\
\text { no período de } 2014 \text { a } 2016\end{array}$ & $\begin{array}{l}\text { A incorporação entre crescimento } \\
\text { econômico e prudência ecológica aos } \\
\text { instrumentos de planejamento urbano }\end{array}$ & $\begin{array}{c}\text { Revista } \\
\text { Brasileira de } \\
\text { Gestão Urbana } \\
\end{array}$ \\
\hline $\begin{array}{c}\text { Joia, } \\
\text { Anunciação \& } \\
\text { Paixão (2018) }\end{array}$ & $\begin{array}{c}\text { Implicações do uso e ocupação do solo para o } \\
\text { planejamento e gestão ambiental da Bacia } \\
\text { Hidrográfica do Rio Aquidauana, Mato Grosso } \\
\text { do Sul } \\
\end{array}$ & $\begin{array}{c}\text { Subsídios para a gestão da bacia } \\
\text { hidrográfica, estimando o seu número } \\
\text { de habitantes e a sua área }\end{array}$ & $\begin{array}{l}\text { Interações } \\
\text { (Campo } \\
\text { Grande) }\end{array}$ \\
\hline $\begin{array}{c}\text { Schueler, } \\
\text { Kzure \& } \\
\text { Racca }(2018)\end{array}$ & $\begin{array}{l}\text { Como estão os resíduos urbanos nas favelas } \\
\text { cariocas? }\end{array}$ & $\begin{array}{c}\text { Alternativas capazes de reduzir a } \\
\text { dificuldade de manejo do material e } \\
\text { facilitar a sua coleta }\end{array}$ & $\begin{array}{c}\text { Revista } \\
\text { Brasileira de } \\
\text { Gestão Urbana }\end{array}$ \\
\hline $\begin{array}{c}\text { Vieira \& } \\
\text { Saurin (2018) }\end{array}$ & $\begin{array}{c}\text { Análise de acidente ambiental: estudo de caso } \\
\text { usando o Método de Análise da Ressonância } \\
\text { Funcional }\end{array}$ & $\begin{array}{l}\text { O caso de um acidente ambiental em } \\
\text { que houve elevada mortandade de } \\
\text { peixes }\end{array}$ & $\begin{array}{l}\text { Engenharia } \\
\text { Sanitária e } \\
\text { Ambiental }\end{array}$ \\
\hline
\end{tabular}




\begin{tabular}{|c|c|c|c|}
\hline $\begin{array}{c}\text { Silva et al. } \\
(2018)\end{array}$ & $\begin{array}{c}\text { Barreiras à gestão da cadeia de suprimentos verde } \\
\text { na indústria automotiva }\end{array}$ & $\begin{array}{c}\text { Barreiras e análise do grau de influência } \\
\text { na Gestão da Cadeia de Suprimentos } \\
\text { Verde }\end{array}$ & $\begin{array}{c}\text { Revista de } \\
\text { Administração } \\
\text { de Empresas }\end{array}$ \\
\hline Faria (2018) & $\begin{array}{c}\text { O relato da informação financeira de } \\
\text { responsabilidade social como contributo para a } \\
\text { performance das empresas portuguesas }\end{array}$ & $\begin{array}{c}\text { Informação de responsabilidade social } \\
\text { no nível financeiro X atratividade e } \\
\text { performance organizacional. }\end{array}$ & $\begin{array}{c}\text { Gestão \& } \\
\text { Produção }\end{array}$ \\
\hline $\begin{array}{c}\text { Pereira, } \\
\text { Paredes \& } \\
\text { Okawa (2018) }\end{array}$ & $\begin{array}{c}\text { Diagnóstico preliminar da integridade ambiental } \\
\text { de fundos de vale }\end{array}$ & $\begin{array}{c}\text { Elaboração de ferramenta de avaliação } \\
\text { prévia sob a totalidade ambiental de } \\
\text { fundos de vale }\end{array}$ & $\begin{array}{c}\text { Engenharia } \\
\text { Sanitária e } \\
\text { Ambiental }\end{array}$ \\
\hline $\begin{array}{c}\text { Camasmie \& } \\
\text { Miraglia } \\
(2018)\end{array}$ & $\begin{array}{c}\text { Incidência de dengue c custos associados, nos } \\
\text { períodos anterior (2000-2008) e posterior (2009- } \\
\text { 2013) à construção das usinas hidrelétricas em } \\
\text { Rondônia }\end{array}$ & $\begin{array}{c}\text { A incidência de dengue e os custos } \\
\text { associados diante a construção das } \\
\text { usinas hidrelétricas em Rondônia, } \\
\text { Brasil }\end{array}$ & $\begin{array}{c}\text { Epidemiologia e } \\
\text { Serviços de } \\
\text { Saúde }\end{array}$ \\
\hline $\begin{array}{c}\text { Ferreira et al. } \\
(2018)\end{array}$ & $\begin{array}{c}\text { Governança colaborativa e gestão de bacias } \\
\text { hidrográficas nas reservas da biosfera no Brasil e } \\
\text { no Canadá }\end{array}$ & $\begin{array}{c}\text { Comparação de ambientes regulatórios } \\
\text { e desconstruídos como uma das } \\
\text { prioridades para a governança das } \\
\text { bacias hidrográficas e a gestão } \\
\text { ambiental dentro de duas reservas da } \\
\text { Biosfera da UNESCO }\end{array}$ & $\begin{array}{c}\text { Ambiente \& } \\
\text { Água }\end{array}$ \\
\hline $\begin{array}{c}\text { Pereira, Curi } \\
\text { \& Curi (2018) }\end{array}$ & $\begin{array}{c}\text { Uso de indicadores na gestão dos resíduos sólidos } \\
\text { urbanos: uma proposta metodológica de } \\
\text { construção e análise para municípios e regiões }\end{array}$ & $\begin{array}{c}\text { Modelo para avaliação da gestão dos } \\
\text { resíduos sólidos urbanos }\end{array}$ & $\begin{array}{c}\text { Engenharia } \\
\text { Sanitária e } \\
\text { Ambiental }\end{array}$ \\
\hline
\end{tabular}

No entanto, algumas publicações, em outros idiomas (espanhol e inglês), abordando esse tema, foram identificadas na plataforma pesquisada, demonstrando a busca de uma maior visibilidade internacional por parte dos pesquisadores brasileiros em relação aos seus estudos sobre essa temática, assim como o crescimento de parcerias com instituições e grupos de pesquisa de outros países.

O Quadro 2 mostra que a temática gestão ambiental passou, recentemente, a receber um enfoque multidisciplinar e, por vezes, interdisciplinar, mais relacionado ao conceito proposto por Barbieri (2016) e Seiffert (2014). Esses autores consideram que o escopo da gestão ambiental vai além do gerenciamento em si, abordando outras perspectivas, como a sustentabilidade, a gestão de resíduos sólidos e a responsabilidade socioambiental empresarial.

Além disso, pode-se inferir que os estudos relacionados à busca por práticas e meios mais adequados de exploração dos recursos naturais também aumentaram, em conformidade com a ótica de Rodriguez \& Silva (2013), segundo a qual, a gestão ambiental deve possuir tal finalidade.

\section{Conclusão}

Os estudos científicos abordando a temática gestão ambiental publicados ao longo da última década e depositados na plataforma Scielo relacionam-se, principalmente, às áreas da gestão da produção e da qualidade, prevalecendo análises de casos de empresas, seus sistemas, práticas, certificações e averiguação de potenciais impactos ao meio ambiente, principalmente em indústrias instaladas no Sul e Sudeste do Brasil.

No entanto, recentemente, aumentou a quantidade de pesquisas de caráter multi e até interdisciplinar, assim como as parcerias entre pesquisadores brasileiros e de outros países referentes a esse tema.

Pesquisas sobre gestão ambiental, dada a relevância desse assunto, merecem maior abrangência e destaque por parte de autores, periódicos, grupos e instituições de pesquisa nacionais e internacionais.

A quantidade e a qualidade dessas pesquisas, bem como o apoio para que sejam realizadas, são indispensáveis para o desenvolvimento sustentável das organizações e da sociedade em geral.

Este estudo, além de expor as abordagens que vêm sendo dadas às publicações nessa área, também buscou incentivar outros pesquisadores que se interessem por essa temática importante e atual.

\section{Referências}

Abe, K. C.; Miraglia, S. G. K. 2018. Incidência de dengue e custos associados, nos períodos anterior (2000-2008) e posterior (20092013) à construção das usinas hidrelétricas em Rondônia. Epidemiologia e Serviço de Saúde, 27, (2), 1-10. http://dx.doi.org/10.5123/s167949742018000200012.

Alperstedt, G. D.; Quintella, R. H.; Souza, L. R. 2010. Estratégias de gestão ambiental e seus fatores determinantes: uma análise institucional. Revista de Administração de Empresas, 50, (2), 170-186. http://dx.doi.org/10.1590/S003475902010000200004.

Amazonas, I. T.; Silva, R. F. C. Andrade, M. O. 2018. Gestão ambiental hoteleira: tecnologias e práticas sustentáveis aplicadas 
a hotéis. Ambiente \& Sociedade, 21, 1-20.

http://dx.doi.org/10.1590/1809-

4422asoc0172r2vu1811ao.

Assis, W. D.; Ribeiro, M. M. R.; Moraes, M. M.

G. A. 2018. Proposição de melhorias para o

Sistema de Cobrança pelo Uso da Água

Bruta da Bacia Hidrográfica do Rio São

Francisco. Engenharia Sanitária e

Ambiental, 23, (4), 779-790.

http://dx.doi.org/10.1590/s141341522018163489.

Barbieri, J. C. 2016. Gestão ambiental empresarial: conceitos, modelos e instrumentos. 4. ed. São Paulo: Saraiva.

Bardin L. 2011. Análise de conteúdo. São Paulo: Edições 70.

Calegari, L.; Martins, S. V.; Gleriani, J. M.; Silva, E.; Busato, L. C. 2010. Análise da dinâmica de fragmentos florestais no município de Carandaí, MG, para fins de restauração florestal. Revista Árvore, 34, (5), 871-880. http://dx.doi.org/10.1590/S010067622010000500012.

Cavalcanti, A. P. B. 2010. Implantação de programas de manejo e plano de gestão ambiental em pequenas comunidades. Sociedade \& Natureza, 22, (3), 539-550.

Ceconi, E. D.; Piccilli, D. G. A.; Bernardi, F.; Fensterseifer, P. 2018. Análise de vulnerabilidade visando o planejamento ambiental em bacia de captação para abastecimento público. Ambiente \& Sociedade, 21, 22p. http://dx.doi.org/10.1590/18094422asoc0078r2vu1811ao.

Curi, D. 2011. Gestão ambiental. São Paulo: Pearson Prentice Hall.

Faria, M. J. S. 2018. O relato da informação financeira de responsabilidade social como contributo para a performance das empresas portuguesas. Gestão \& Produção, 25, (4), 866-887. http://dx.doi.org/10.1590/0104530x3342-18.

Ferreira, M. I. P.; Shaw, P.; Sakaki, G. K.; Alexander, T.; Donnini, J. G. B.; Rego, V. V. B. S. 2018. Governança colaborativa e gestão de bacias hidrográfica em reservas de biosfera no Brasil e Canadá. Revista Ambiente \& Água, 13, (3), 1-11. http://dx.doi.org/10.4136/ambi-agua.2225.

Fonseca, S. A, Martins, P. S. 2010. Gestão ambiental: uma súplica do planeta, um desafio para políticas públicas, incubadoras e pequenas empresas. Production, 20, (4), 538-548. http://dx.doi.org/10.1590/S010365132010005000056.
Fonseca, S. A.; Souza, S. B.; Jabbour, C. J. C. 2010. Desafios e oportunidades das incubadoras de empresas para a incorporação de estratégias ambientais. Organizações \& Sociedade, 17, (53), 331344.

Freitas, A. L. P.; Almeida, G. M. M. 2010. Avaliação do nível de consciência ambiental em meios de hospedagem: uma abordagem exploratória. Sociedade \& Natureza, 22, (2), 405-417.

Gil, A. C. 2008. Métodos e técnicas de pesquisa social. 6. ed. São Paulo: Atlas.

Grael, P. F. F.; Oliveira, O. J. 2010. Sistemas certificáveis de gestão ambiental e da qualidade: práticas para integração em empresas do setor moveleiro. Production, 20, (1), 30-41.

Joia, P. R.; Anunciação, V. S. D.; Paixão, A. A. D. 2018. Implicações do uso e ocupação do solo para o planejamento e gestão ambiental da Bacia Hidrográfica do Rio Aquidauana, Mato Grosso do Sul. Interações (Campo Grande), 19, (2), 343-358.

Lakatos, E. M.; Marconi, M. A. 2003. Fundamentos de metodologia científica. 5. ed. São Paulo: Atlas.

Mechi, A.; Sanches, D. L. 2010. Impactos ambientais da mineração no Estado de São Paulo, Estudos Avançados, 24, (68), 209220.

Nascimento, S. M. M. G.; Gomes, J. M. A. 2018. Planejamento e orçamento municipal de Teresina para o crescimento econômico e meio ambiente no período de 2014 a 2016. URBE - Revista Brasileira de Gestão Urbana, 10, (3), 695-707. http://dx.doi.org/10.1590/21753369.010.003.ao15.

Oliveira, O. J.; Pinheiro, C. R. M. S. 2010. Implantação de sistemas de gestão ambiental ISO 14001: uma contribuição da área de gestão de pessoas. Gestão \& Produção, 17, (1), 51-61.

Oliveira, O. J.; Serra, J. R. M. 2010. Benefícios e dificuldades da gestão ambiental com base na ISO 14001 em empresas industriais de São Paulo. Production, 20, (3), 429-438. http://dx.doi.org/10.1590/S010365132010005000013.

Pereira, S. S.; Curi, R. C.; Curi, W. F. 2018. Uso de indicadores na gestão dos resíduos sólidos urbanos: uma proposta metodológica de construção e análise para municípios e regiões. Engenharia Sanitária e Ambiental, 23, (3), 471-483. 
http://dx.doi.org/10.1590/s1413-

41522018162872.

Pereira, P. P.; Paredes, E. A.; Okawa, C. M. 2018.

Diagnóstico preliminar da integridade ambiental de fundos de vale. Engenharia Sanitária e Ambiental, 23, (4), 739-749.

Rego, F. L. H.; Brand, A. J.; Costa, R. B. 2010. Recursos genéticos, biodiversidade, conhecimento tradicional Kaiowá e Guarani e o desenvolvimento local. Interações (Campo Grande), 11, (1), 55-69.

Rodriguez, J. M. M.; Silva, E. V. Planejamento e gestão ambiental: subsídios da geoecologia das paisagens e da teoria geossistêmica. Fortaleza: Edições UFC.

Seiffert, M. E. B., 2014. Gestão ambiental: instrumentos, esferas de ação e educação ambiental. 3. ed. São Paulo: Atlas.

Sellitto, M. A.; Borchardt, M.; Pereira, G. M. 2010. Modelagem para avaliação de desempenho ambiental em operações de manufatura. Gestão \& Produção, 17, (1), 95-109.

Silva, F. C.; Shibao, F. Y.; Barbieri, J. C.; Librantz, A. F. H.; Santos, M. R. 2018.
Barreiras à gestão da cadeia de suprimentos verde na indústria automotiva. Revista de Administração de Empresas, 58, (2), 149162. http://dx.doi.org/10.1590/s0034759020180204.

Schueler, A. S. D.; Kzure, H.; Racca, G. B. Como estão os resíduos urbanos nas favelas cariocas? 2018. URBE - Revista Brasileira de Gestão Urbana, 10, (1), 213-230.

Uehara, T. H. K.; Otero, G. G. P.; Martins, E. G. A.; Philippi Junior, A.; Mantovani, W. 2010. Pesquisas em gestão ambiental: análise de sua evolução na Universidade de São Paulo. Ambiente \& Sociedade, 13, (1), 165-185.

Varjabedian, R. 2010. Lei da Mata Atlântica: retrocesso ambiental. Estudos Avançados, 24, (68), 147-160.

Vieira, L. C.; Saurin, T. A. 2018. Análise de acidente ambiental: estudo de caso usando o Método de Análise da Ressonância Funcional. Engenharia Sanitária e Ambiental, 23, (2), 373-383. http://dx.doi.org/10.1590/s141341522018147114. 